\title{
Plasma-enhanced chemical vapour deposition and structural characterization of amorphous chalcogenide films
}

\author{
(C) P. Nagels \\ RUCA-University of Antwerp \\ B-2020 Antwerpen, Belgium
}

(Получена 16 фревраля 1998 г. Принята к печати 23 февраля 1998 г.)

\begin{abstract}
We describe the preparation of layers of amorphous $\mathrm{Se}, \mathrm{As}_{x} \mathrm{~S}_{1-x}, \mathrm{As}_{x} \mathrm{Se}_{1-x}, \mathrm{Ge}_{x} \mathrm{~S}_{1-x}$ and $\mathrm{Ge}_{x} \mathrm{Se}_{1-x}$ by plasmaenhanced chemical vapour deposition using the hydrides of the elements as precursor gases. We discuss the influence of the gas ratios and the deposition conditions (pressure, rf power input) on the chemical composition and the homogeneity of the binary systems. Information concerning the structure of the films was obtained from infrared and Raman spectroscopy.
\end{abstract}

\section{Introduction}

Intensive research on amorphous chalcogenides started about 30 years ago, mainly under the impulse of B.T. Kolomiets in the Joffe Institute, Russia. A first milestone in the study of these materials was the discovery in 1968 by Ovshinsky of non-destructive switching in thin films of amorphous multicomponent chalcogenides. Reliable switching and memory devices were produced but their penetration in the market was not succesful. A second milestone was the observation that illumination with bandgap light of thin chalcogenide films resulted in a blue shift (photobleaching) of red shift (photodarkening) of the absorption edge. This change in optical properties is accompanied by change of some other properties, e.g. density, elastic constants, electronic properties, photodissolution of metals, etc. In the studies related to the above-mentioned fields the films were usually prepared by thermal evaporation or by sputtering, i.e. the solid state is realized by rapid condensation of the vapours. The as-deposited films have a more or less disordered network.

In our study we have prepared films of amorphous chalcogenides, including elemental $\mathrm{Se}$ and the binary As and Ge chalcogenides $\mathrm{As}_{x} \mathrm{~S}_{1-x}, \mathrm{As}_{x} \mathrm{Se}_{1-x}, \mathrm{Ge}_{x} \mathrm{~S}_{1-x}, \mathrm{Ge}_{x} \mathrm{Se}_{1-x}$, by plasma-enhanced chemical vapour deposition (PECVD), a technique widely used for the preparation of amorphous silicon. In amorphous silicon the incorporation of hydrogen during the plasma-deposition process plays a very important role in saturating the dangling bonds responsible for high densities of electrically active gap states. The effect of hydrogen incorporation in amorphous chalcogenides on the basic physical properties is probably not that drastic. Indeed, the defect chemistry of chalcogenide glasses differs greatly from that of the tetrahedrally coordinated amorphous semiconductors. It is generally accepted that neutral dangling bonds are transformed into positively and negatively charged dangling bonds pinning the Fermi level close to the middle of the gap.

The purpose of our study is to make a comparison between the structure and the photo-induced effects of amorphous chalcogenide films prepared either by plasma decomposition or by vacuum evaporation. In this way we hope to get some futher insight into the origin of the structure-related phenomena. Furthermore, we believe that PECVD is a promising technique for growing layers of amorphous chalcogenides, in particular with respect to their possible technological application.

\section{Material preparation by PECVD}

We have deposited thin films of amorphous Se, $\mathrm{As}_{x} \mathrm{~S}_{1-x}$, $\mathrm{As}_{x} \mathrm{Se}_{1-x}, \mathrm{Ge}_{x} \mathrm{~S}_{1-x}$ and $\mathrm{Ge}_{x} \mathrm{Se}_{1-x}$ (1 to $2 \mu \mathrm{m}$ thick) in a plasma discharge stainless steel reactor. The precursor gases were high purity hydrides, $\mathrm{H}_{2} \mathrm{Se}, \mathrm{H}_{2} \mathrm{~S}, \mathrm{AsH}_{3}$ and $\mathrm{GeH}_{4}$, pure or diluted in hydrogen ( $15 \mathrm{vol} \%$ of the hydrides). A low pressure plasma, varying between 0.1 to $1 \mathrm{mbar}$, was created by an rf discharge $(13.56 \mathrm{MHz})$ between two parallel plate electrodes, $8 \mathrm{~cm}$ in diameter. The reactant gases were mixed before entering the reactor and were admitted through an inlet in the reactor wall at the height of the electrodes. The gases were pumped away through an outlet at the opposite side, so that the gas flow was parallel with the electrodes. The rf power coupled into the reactor varied from 10 to $80 \mathrm{~W}$. Crystalline silicon and glass substrates were fixed on both electrodes. Depositions were made without additional heating of the substrates by a furnace, but due to plasma heating the temperature was approximately $50^{\circ} \mathrm{C}$.

For determination of the chemical composition of the layers, a silicon platelet was positioned from the middle to the gas inlet side of both the grounded and powered electrode. The atomic ratios of the elements were measured in the middle of the platelet at regular distances by means of electron microprobe analysis. Infrared transmission spectra were recorded in the wavenumber range from 4000 to $150 \mathrm{~cm}^{-1}$ on films deposited onto polished crystalline $\mathrm{Si}$ wafers using a Beckman 4240 and a Bruker IFV 113 spectrometers. Raman measurements were made with the help of a Bruker $66 \mathrm{~V}$ spectrometer in a reflection mode using a $1.06 \mu \mathrm{m}$ YAG: $\mathrm{Nd}^{+3}$ laser source. 


\section{Composition analysis and structural properties}

\subsection{Amorphous selenium (a-Se)}

Films of $a$-Se were deposited using pure $\mathrm{H}_{2} \mathrm{Se}$. The deposition conditions were: flow rate $6 \mathrm{sccm}$; pressure $0.1 \mathrm{mbar}$; rf power $30 \mathrm{~W}$; deposition time $10 \mathrm{~min}$; film thickness $\sim 1 \mu \mathrm{m}$. Films growth only occurred on the grounded electrode. X-ray diffraction showed that the film was completely amorphous.

From the knowledge that the short-range order in crystalline and amorphous materials is generally the same, it is reasonable to assume that the two existing crystalline allotropes of Se can be present in amorphous Se. The stable form of crystalline Se is trigonal. Its lattice consists of spiral-like chains parallel to the $\mathbf{c}$-axis. The helices contain three atoms per turn and are in an hexagonal array (close packing for rods). The interchain bonding is covalent, while the intrachain bonding is due to weaker Van der Waals attractions. Two similar metastable monoclinic forms of crystalline Se exist, $\alpha$-monoclinic Se and $\beta$-monoclinic Se. The structural unit in both structures is a finite molecule in the form of a $\mathrm{Se}_{8}$ ring. The difference between the $\alpha$ - and $\beta$-monoclinic allotropes is a different stacking pattern within the respective unit cells. Thus monoclinic Se is molecular, whereas trigonal Se is polymeric. In all three crystalline forms, selenium is twofold coordinated and the covalent bond lengh is essentially the same $(2.32 \AA)$. In the past the structure of amorphous Se has been studied by several authors using different techniques. By ordinary analysis of the X-ray radial distrubution functions it is difficult to differentiate rings from chains and these results have been interpreted in very different manners. A clearer picture of the structure of amorphous Se emerges from Raman spectroscopy. These experiments gave evidence that the amorphous state can consist of the two allotropic forms which are mixed together: one is the $\mathrm{Se}_{8}$ ring and the other form is the helical chain. The Raman spectrum of an as-deposited Se film is shown in Fig. 1,a. It shows a strong peak at $250 \mathrm{~cm}^{-1}$ and two small bands at 80 and $112 \mathrm{~cm}^{-1}$. Moreover, a small shoulder appears at $235 \mathrm{~cm}^{-1}$ on the $250 \mathrm{~cm}^{-1}$ band. We also recorded the Raman spectra of an amorphous Se film prepared by vacuum evaporation and of a bulk glass quenched from $250^{\circ} \mathrm{C}$. Both spectra were similar to that of the plasma CVD film. The Raman peaks of amorphous Se have been identified by Lucovsky et al. [1]. They observes a much closer resemblance of the Raman spectrum of melt quenched selenium to that of $\mathrm{Se}_{8}$ in monoclinic Se than to that of trigonal Se. In that paper they assigned the dominant peak at $250 \mathrm{~cm}^{-1}$ and the smaller bands at 80 and $112 \mathrm{~cm}^{-1}$ to vibrations in the $\mathrm{Se}_{8}$ ring. In trigonal Se the predominant Raman band lies at $235 \mathrm{~cm}^{-1}$. In a later paper Lucovsky [2] formulated some objections against a structural model which presumes a significant ring fraction in amorphous Se. He presented an alternative interpretation of the vibrational spectra that does not require
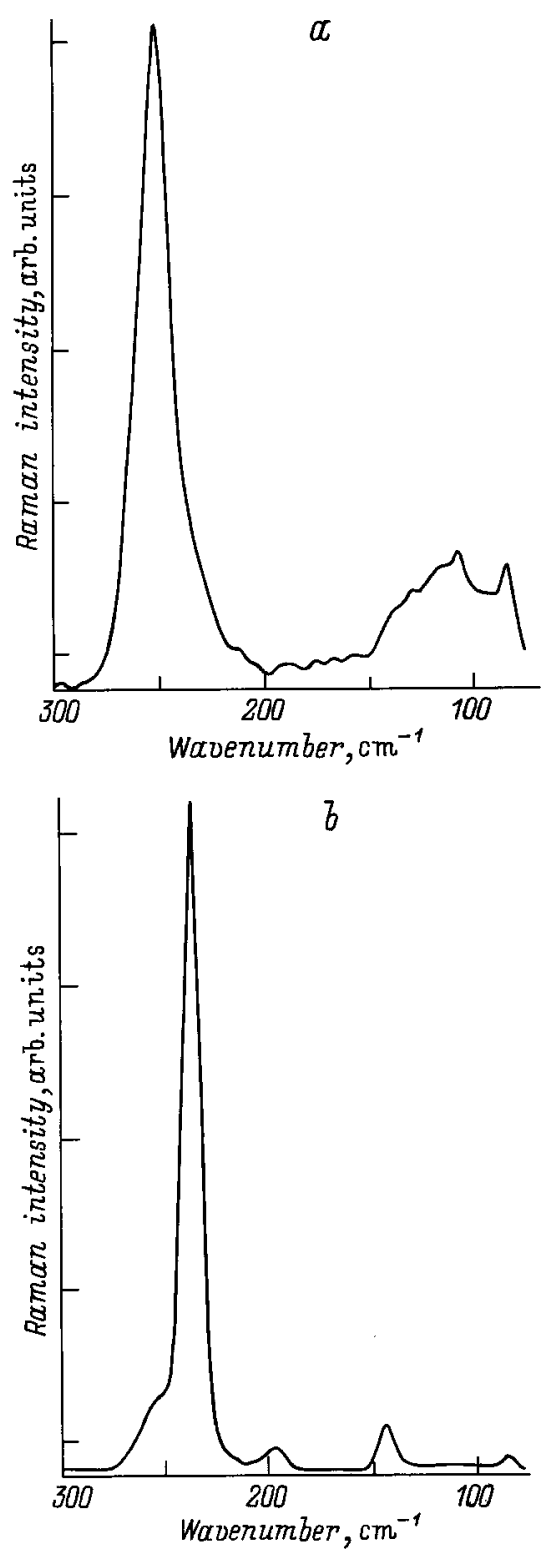

Figure 1. Raman spectra of as-deposited amorphous Se film $(a)$ and annealed at $150^{\circ} \mathrm{C}$ for $1 \mathrm{~h}(b)$.

discrete molecules. He proposed a structural model based on chains which include both helical chain-like and ring-like segments of the Se atoms (a "meandering" chain). Lucovsky assumed that a band at around $250 \mathrm{~cm}^{-1}$ can originate from bond stretching vibrations in $\mathrm{Se}_{8}$ fragments as well as in chain fragments. If we adopt these ideas then the Raman spectrum of our plasma CVD film indicates that the structure contains predominantly $\mathrm{Se}_{8}$ rings and $\mathrm{Se}_{8}$ molecular ring fragments containing 5 and $6 \mathrm{Se}$ atoms. The band at $250 \mathrm{~cm}^{-1}$ can be assigned to bond stretching vibrations and the band at $112 \mathrm{~cm}^{-1}$ to bond bending vibrations in the meandering chain. The shoulder that appears at $235 \mathrm{~cm}^{-1}$ can be associated with a small fraction of "pure" helical chains. There is another piece of experimental evidence that speaks against a structural model which assumes a dominant 
fraction of $\mathrm{Se}_{8}$ rings in amorphous Se. In the evaporated Se film we observed an identical Raman spectrum. In the past the composition of selenium vapour has been studied by a variety of experimental techniques. It is generally accepted that the vapour contains types of species with predominance of $\mathrm{Se}_{5}, \mathrm{Se}_{2}, \mathrm{Se}_{4}$ and $\mathrm{Se}_{7}$ fragments. The $\mathrm{Se}_{8}$ ring is not a favoures species in the vapour phase and it seems unlikely that a rearrangement of the shorter molecular species to form eight-membered rings will occur on the substrate as the amorphous state is deposited.

Upon heating at $150^{\circ} \mathrm{C}$ for $1 \mathrm{~h}$ the film was crystallized. The Raman spectrum (see Fig. 1,b) showed a sharp peak at $235 \mathrm{~cm}^{-1}$ and a small shoulder at $250 \mathrm{~cm}^{-1}$. Upon crystallization the meander-like chains and the $\mathrm{Se}_{8}$ rings undergo transformation to the orderly array of chains of trigonal Se.

\subsection{Amorphous $A \mathbf{s}_{x} \mathrm{~S}_{1-x}$}

Details of this work have already been reported in previous publications [3]. In order to get layers in a broad chemical composition range the $\mathrm{AsH}_{3} / \mathrm{H}_{2} \mathrm{~S}$ ratio was varied from $1 / 3$ to $1 / 99$. The decomposition of $\mathrm{AsH}_{3}$ is exothermic $\left(\Delta H^{\circ}=+715 \mathrm{~kJ} \cdot \mathrm{mol}^{-1}\right)$, whereas the decomposition of $\mathrm{H}_{2} \mathrm{~S}$ is endothermic $\left(\Delta H^{\circ}=-259 \mathrm{~kJ} \cdot \mathrm{mol}^{-1}\right)$; thus we expect more rapid and complete dissociation of $\mathrm{AsH}_{3}$. In Fig. 2 the As content of the layers expressed in at.\% is given for the various $\mathrm{AsH}_{3} / \mathrm{H}_{2} \mathrm{~S}$ ratios. The composition of each layer was measured from the middle of the powered electrode $(z=0)$ to its outer circumference at regular distances. The deposition conditions were: pressure $0.25 \mathrm{mbar}$; rf power $15 \mathrm{~W}$.

In agreement with previous work by Fritzsche et al. [4], we observed that the composition of the film deposited at a given $\mathrm{AsH}_{3} / \mathrm{H}_{2} \mathrm{~S}$ ratio changed with the position $z$ on the substrate along the gas flow direction. The chemical

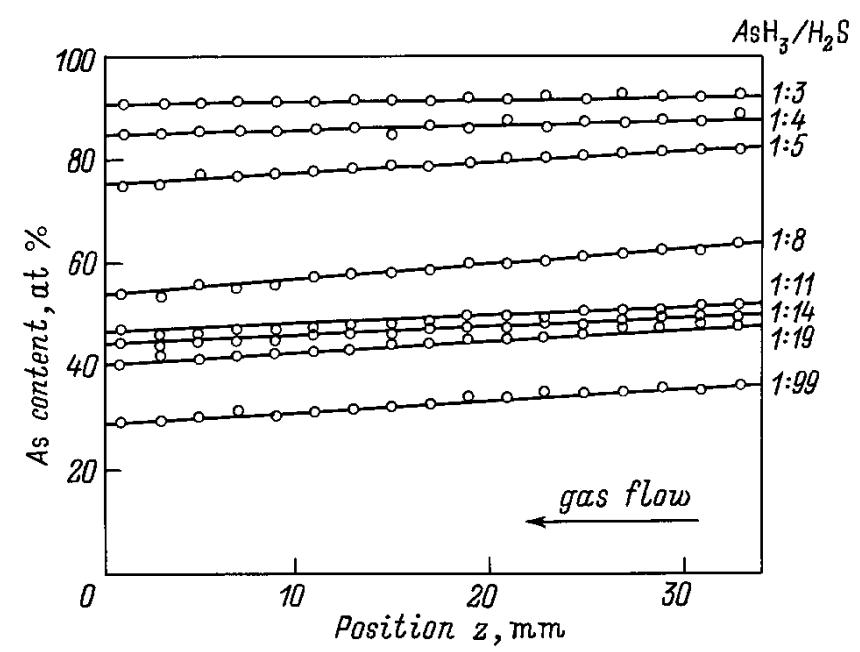

Figure 2. As content of $\mathrm{As}_{x} \mathrm{~S}_{1-x}$ layers vs. sample position $z$ on the powered electrode for various $\mathrm{AsH}_{3} / \mathrm{H}_{2} \mathrm{~S}$ ratios $(z=0$ : middle of the electrode).

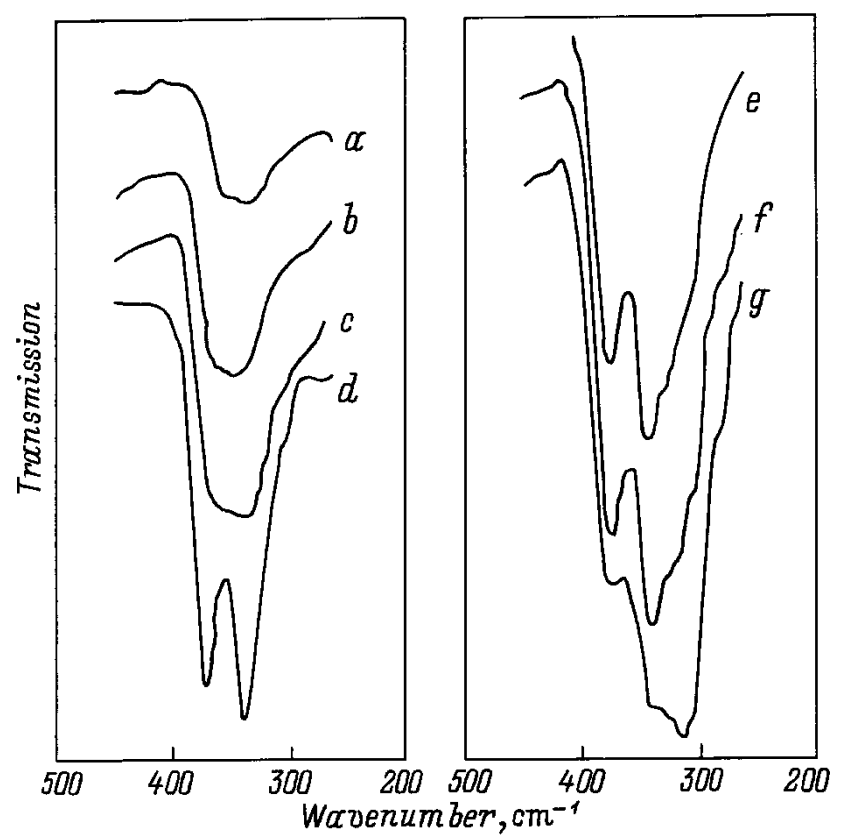

Figure 3. IR spectra of $\mathrm{As}_{x} \mathrm{~S}_{1-x}$ layers deposited on the powered electrode with $x=0.90(a) ; 0.86(b) ; 0.78(c) ; 0.60(d) ; 0.48(e)$; $0.46(f) ; 0.43(g)$.

homogeneity was better in the samples with the highest As content. In Fig. 3 are shown IR spectra recorded in the range $500 \div 200 \mathrm{~cm}^{-1}$ on layers of different chemical composition. The IR spectrum of the nearly stoichiometric layer $(x=0.42)$ clearly manifests a strong absorption mode at $311 \mathrm{~cm}^{-1}$, which corresponds to an asymmetric stretching vibration in a $\mathrm{AsS}_{3}$ pyramid, the structural unit in crystalline $\mathrm{As}_{2} \mathrm{~S}_{3}$. In layers richer in As $(x>0.42)$ two strong absorption bands at 341 and $374 \mathrm{~cm}^{-1}$ become dominant. The IR spectra of the crystalline modifications of $\mathrm{As}_{4} \mathrm{~S}_{4}$ and $\mathrm{As}_{4} \mathrm{~S}_{3}$ show absorption bands close to those observed in our spectra: 346 and $374 \mathrm{~cm}^{-1}$ in an $\mathrm{As}_{4} \mathrm{~S}_{4}$ crystal; 341 and $370 \mathrm{~cm}^{-1}$ in an $\mathrm{As}_{4} \mathrm{~S}_{3}$ crystal. Because of the small differences in wavenumber for the crystals, the 341 and $374 \mathrm{~cm}^{-1}$ band in our spectra may be due to vibrations of $\mathrm{As}_{4} \mathrm{~S}_{4}$ units or of $\mathrm{As}_{4} \mathrm{~S}_{3}$ units or a mixture of both. From the IR study we may conclude that increasing overstoichiometry of As causes the breaking of As-S bonds with the formation of structural units of the $\mathrm{As}_{4} \mathrm{~S}_{4}$ and $\mathrm{As}_{4} \mathrm{~S}_{3}$ type, containing As-As bonds. Raman spectra gave futher evidence for the presence of $\mathrm{As}_{4} \mathrm{~S}_{4}$ and $\mathrm{As}_{4} \mathrm{~S}_{3}$ molecular units in layers with an As overstoichiometry. Fig. 4 represents Raman spectra of two films with composition $\mathrm{As}_{0.46} \mathrm{~S}_{0.54}(a)$ and $\mathrm{As}_{0.78} \mathrm{~S}_{0.22}(b)$. Spectrum $a$ showes a strong peak at $340 \mathrm{~cm}^{-1}$ attributed to vibrational modes of pyramidal $\mathrm{AsS}_{3}$ units. Two meaker bands, clearly visible in spectrum $a$, located at $235 \mathrm{~cm}^{-1}$ and $188 \mathrm{~cm}^{-1}$ indicate the presence of $\mathrm{As}_{4} \mathrm{~S}_{4}$ units. In an As-rich sample with $x=0.78$ a narrow peak appears at $273 \mathrm{~cm}^{-1}$ (see Fig. 4, $b$ ), which is the most intense band in the Raman spectrum of crystalline $\mathrm{As}_{4} \mathrm{~S}_{3}$. 

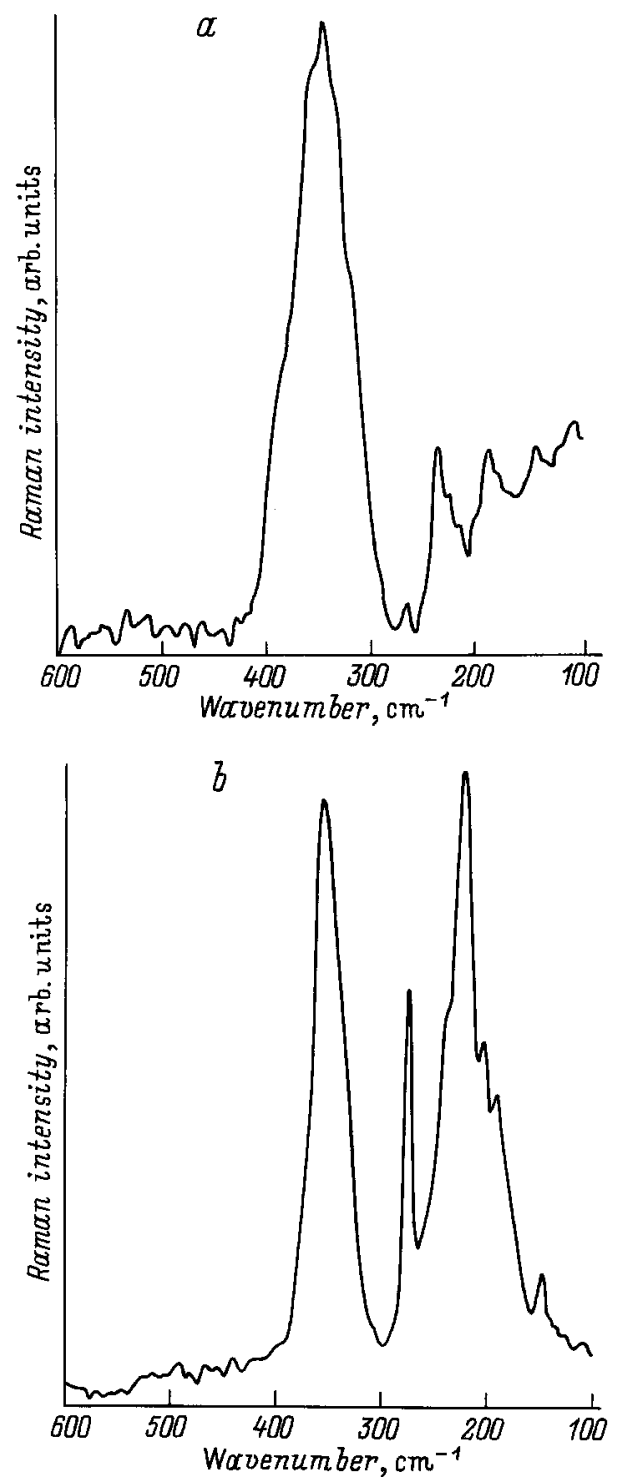

Figure 4. Raman spectra of $\mathrm{As}_{x} \mathrm{~S}_{1-x}$ layers with $x=0.46(a)$ and $0.78(b)$.

The strong band at $219 \mathrm{~cm}^{-1}$ in spectrum $b$ can be assigned to pure As clusters. In a layer with very high As content $\left(\mathrm{As}_{0.90} \mathrm{~S}_{0.10}\right)$ the peak at $340 \mathrm{~cm}^{-1}$ associated with $\mathrm{AsS}_{3}$ units is drastically reduced and the band at around $210 \mathrm{~cm}^{-1}$ typical of amorphous As, becomes the dominant feature in the Raman spectrum.

\subsection{Amorphous $\mathrm{As}_{x} \mathrm{Se}_{1-x}$}

The chemical composition of the $\mathrm{As}_{x} \mathrm{Se}_{1-x}$ films obtained for the various gas ratios is listed in Table. All compositions were in the Se-rich side compared to the stoichiometric composition $\mathrm{As}_{0.40} \mathrm{Se}_{0.60}$. An increase of the $\mathrm{AsH}_{3} / \mathrm{H}_{2} \mathrm{Se}$ ratio from $1 / 2$ to $2 / 1$ did not yield the expected increase in As content. A decrease of the rf power from 60 to $30 \mathrm{~W}$ had a minor effect on the chemical composition.
Chemical composition and optical bandgap $E_{g}$ at room temperature of amorphous $\mathrm{As}_{x} \mathrm{Se}_{1-x}$ films deposited by PECVD

\begin{tabular}{c|c|c}
\hline $\mathrm{AsH}_{3} / \mathrm{H}_{2} \mathrm{Se}$ volume ratio & Chemical composition & $E_{g}, \mathrm{eV}$ \\
\hline $0 / 100$ & $\mathrm{Se}$ & 1.95 \\
$1 / 25$ & $\mathrm{As}_{0.08} \mathrm{Se}_{0.92}$ & 1.95 \\
$1 / 7$ & $\mathrm{As}_{0.20} \mathrm{Se}_{0.80}$ & 1.93 \\
$1 / 2$ & $\mathrm{As}_{0.31} \mathrm{Se}_{0.69}$ & 1.89 \\
$2 / 1$ & $\mathrm{As}_{0.36} \mathrm{Se}_{0.64}$ & 1.83
\end{tabular}

Information concerning the structure of the films was obtained from Raman spectroscopy. Based on the work of Lucovsky [2], it is generally accepted that the structure of amorphous Se consists of chains which include both helical chain-like and ring-like segments of Se atoms. A stoichiometric $\mathrm{As}_{0.40} \mathrm{Se}_{0.60}$ glass is considered to be built up by pyramidal $\mathrm{AsSe}_{3}$ units with the three-fold coordinated As atom at the apex. The pyramids are interconnected by the two-fold coordinated Se atoms. When extra Se atoms are added to the stoichiometric composition, the atoms can be incorporated in the chains linking the pyramidal molecules. This yields a replacement of the As-Se-As links with As-Se-Se-As chains. Thus, for concentrations in the chalcogen-rich regime $(x<0.40) \mathrm{Se}-\mathrm{As}$ and $\mathrm{Se}-\mathrm{Se}$ bonds occur but As-As bonds are excluded. With increasing Se content the number of $\mathrm{Se}-\mathrm{Se}$ units grows, leading to large atomic clusters of Se. The analysis of the Raman spectra of the arsenic selenides is complicated by the fact that the observed frequencies for the chain of pure selenium and the ones for the pyramid and $\mathrm{As}-\mathrm{Se}-\mathrm{Se}-\mathrm{As}$ chains are close to one another.

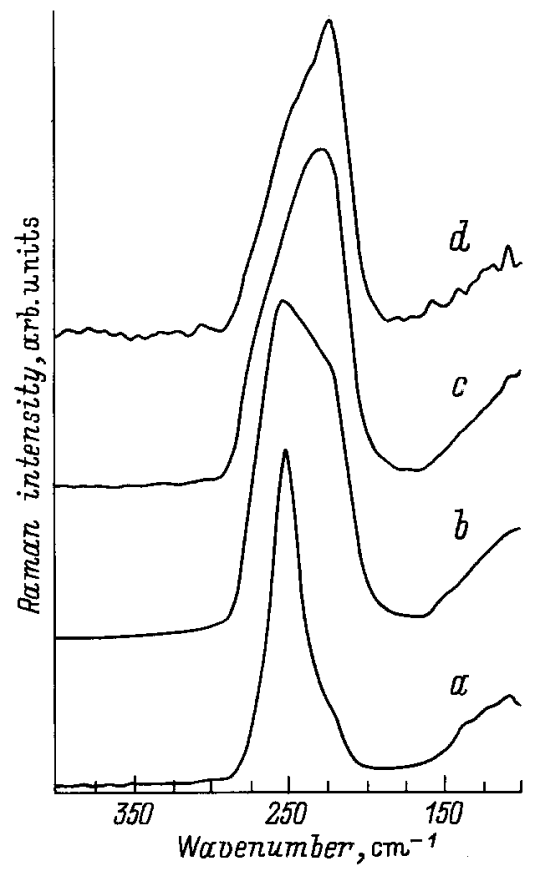

Figure 5. Raman spectra of amorphous $\mathrm{As}_{x} \mathrm{Se}_{1-x}$ films: $a$ - pure $\mathrm{Se} ; b-\mathrm{As}_{0.20} \mathrm{Se}_{0.80} ; c-\mathrm{As}_{0.31} \mathrm{Se}_{0.69}, d-\mathrm{As}_{0.36} \mathrm{Se}_{0.64}$. 
Fig. 5 shows the Raman spectra of amorphous $\mathrm{As}_{x} \mathrm{Se}_{1-x}$ films. The main features can be summarized as follows. In pure Se an intense band occurs at $250 \mathrm{~cm}^{-1}$ with a small shoulder at $235 \mathrm{~cm}^{-1}$. The band at $250 \mathrm{~cm}^{-1}$ has been attributed by Lucovsky [2] to stretching vibrations in a meandering Se chain. The shoulder that appears at $235 \mathrm{~cm}^{-1}$ (typical of crystalline trigonal Se) can be associated with a small fraction of helical chains. At 8 at.\% As the peak at $250 \mathrm{~cm}^{-1}$ is still the dominant spectral feature with a small shoulder at $227 \mathrm{~cm}^{-1}$. A broad band at $227 \mathrm{~cm}^{-1}$ was attributed to an antisymmetric As-Se-As stretching vibration in stoichiometric $\mathrm{As}_{0.40} \mathrm{Se}_{0.60}$. As the As content is increase $(20 \mathrm{at} \%)$ the band at $227 \mathrm{~cm}^{-1}$ grows steadily. The Raman spectrum of 31 at\% As shows a broad band extending from $\sim 200$ to $290 \mathrm{~cm}^{-1}$, which is composed of a band at $227 \mathrm{~cm}^{-1}$ with increased intensity and a side band at $250 \mathrm{~cm}^{-1}$. At $36 \mathrm{at} \%$ the broad band at $227 \mathrm{~cm}^{-1}$, signature of the $\mathrm{AsSe}_{3}$ network, dominates the spectrum.

\subsection{Amorphous $\mathrm{Ge}_{x} \mathrm{~S}_{1-x}$}

The preparation of amorphous $\mathrm{Ge}_{x} \mathrm{~S}_{1-x}$ and $\mathrm{Ge}_{x} \mathrm{Se}_{1-x}$ films by PECVD was discussed in previous publications [5]. For the preparation of the $\mathrm{Ge}-\mathrm{S}$ system, the $\mathrm{GeH}_{4} / \mathrm{H}_{2} \mathrm{~S}$ was varied from $1 / 6$ to $1 / 96$. The total gas pressure was
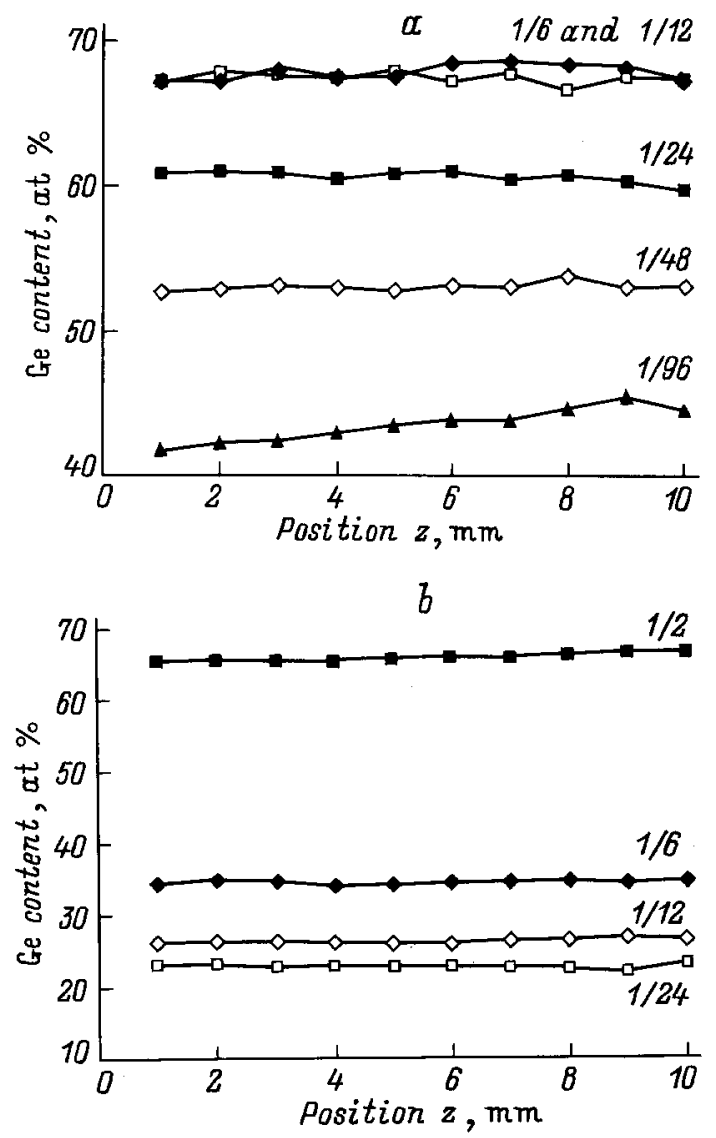

Figure 6. Ge content of amorphous $\mathrm{Ge}_{x} \mathrm{~S}_{1-x}$ layers $(a)$ and of $\mathrm{Ge}_{x} \mathrm{Se}_{1-x}$ layers $(b)(z=10 \mathrm{~mm}$ : middle of the electrode $)$ for various $\mathrm{GeH}_{4} / \mathrm{H}_{2} \mathrm{Se}\left(\mathrm{H}_{2} \mathrm{Se}\right)$ gas ratios.

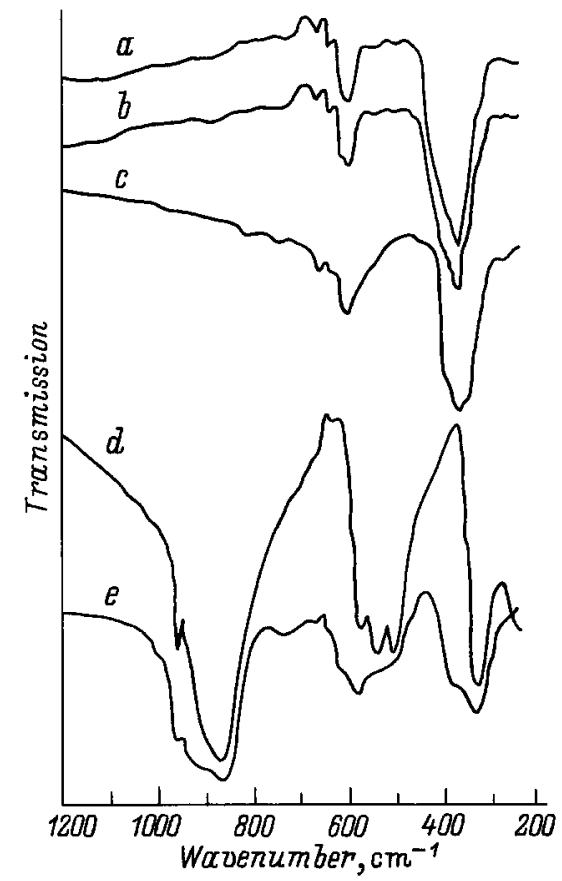

Figure 7. IR spectra of Ge-S layers: $a-\mathrm{Ge}_{0.30} \mathrm{~S}_{0.70}$ as-deposited; $b-\mathrm{Ge}_{0.30} \mathrm{~S}_{0.70}$ after air exposure; $c-\mathrm{Ge}_{0.50} \mathrm{~S}_{0.50}$ as-deposited; $d$ - crystalline $\mathrm{GeO}_{2} ; e-\mathrm{Ge}_{0.50} \mathrm{~S}_{0.50}$ after air-exposure.

kept constant at 0.1 mbar and the rf power input at $20 \mathrm{~W}$. Fig. 6, $a$ shows the Ge content in at.\% of layers deposited on the grounded electrode as a function of the position of the microprobe beam. Although the germanium chalcogenides have been intensivily studied during the last fifteen years, the knowledge of their structure is still ambiguous. Both amorphous $\mathrm{GeS}_{2}$ and $\mathrm{GeSe}_{2}$ have a tetrahedral $X Y_{4}$-type local structure. The ordering of these tetrahedral molecules was explained by different models. Fig. 7 shows IR spectra of a $\mathrm{Ge}_{0.30} \mathrm{~S}_{0.70}$ layer $(a)$ and $\mathrm{Ge}_{0.50} \mathrm{~S}_{0.50}$ layer $(c)$. The strong absorption around $370 \mathrm{~cm}^{-1}$ is the most characteristic feature of the $\mathrm{Ge}-\mathrm{S}$ system. It is usually assigned to the stretching vibration of the $\mathrm{GeS}_{4}$ tetrahedral unit ( $v_{3}$ mode). The IR spectra of both samples recorded after exposure to air for several weeks are also shown in Fig. 7, $b$ and $e$. The Ge-rich film $\left(\mathrm{Ge}_{0.50} \mathrm{~S}_{0.50}\right)$ (spectrum $e$ ) showed strong absorption in a broad range originating from $\mathrm{Ge}-\mathrm{O}$ vibrations. In the same figure the IR absorption spectrum of crystalline $\mathrm{GeO}_{2}$ is represented (spectrum $d$ ). The $\mathrm{GeO}_{2}$ units show three typical vibrations around 860,550 and $330 \mathrm{~cm}^{-1}$. By comparing the spectra of the oxidized $\mathrm{Ge}-\mathrm{S}$ films and the one of $\mathrm{GeO}_{2}$, it is clear that the absorption bands observed in the Ge-rich film after air exposure are a consequence of the formation of $\mathrm{GeO}_{2}$ units.

\subsection{Amorphous $\mathrm{Ge}_{x} \mathrm{Se}_{1-x}$}

Fig. $6, b$ shows the $\mathrm{Ge}$ content of $\mathrm{Ge}_{x} \mathrm{Se}_{1-x}$ layers prepared with a $\mathrm{GeH}_{4} / \mathrm{H}_{2} \mathrm{Se}$ ratio varying from $1 / 2$ to $1 / 24$ at a pressure of $0.1 \mathrm{mbar}$ and an $\mathrm{rf}$ power of $80 \mathrm{~W}$. A broad 


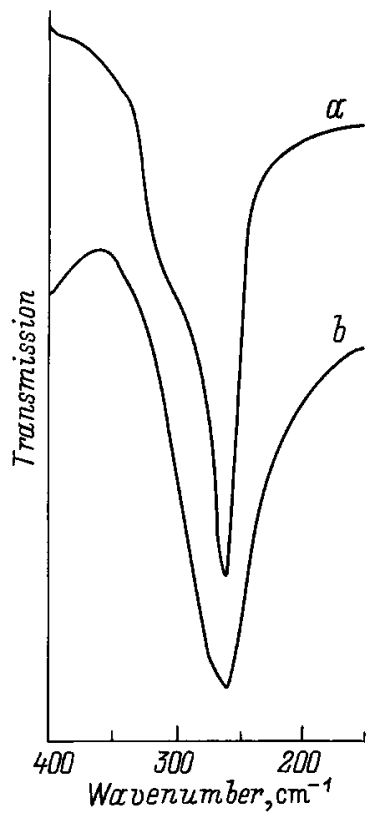

Figure 8. IR spectra of $\mathrm{Ge}_{0.34} \mathrm{Se}_{0.66}(a)$ and $\mathrm{Ge}_{0.64} \mathrm{Se}_{0.36}(b)$.

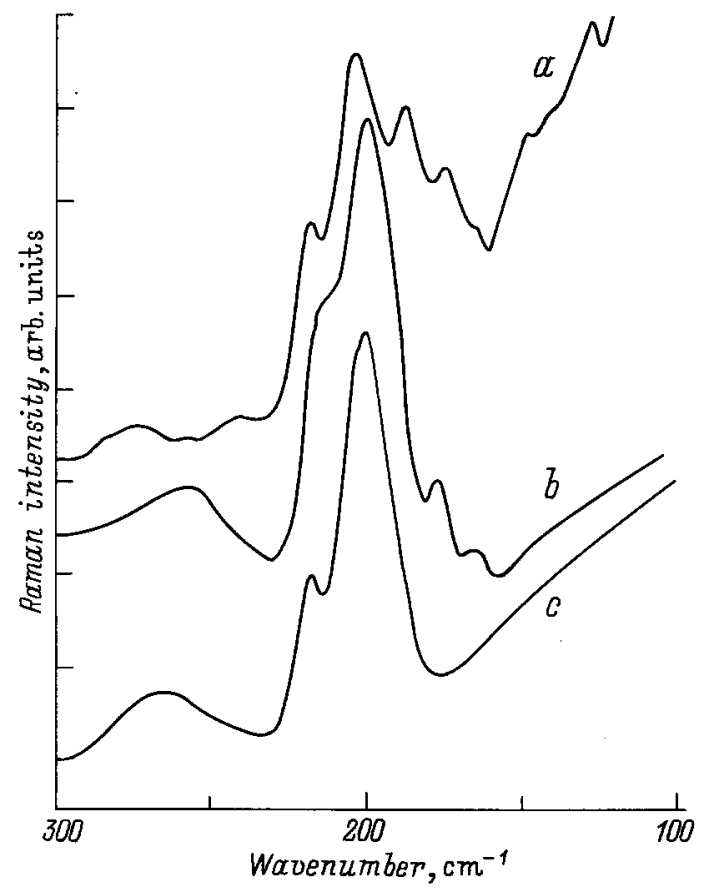

Figure 9. Raman spectra of $\mathrm{Ge}_{0.34} \mathrm{Se}_{0.66}$ as-deposited (a); after annealing at $300^{\circ} \mathrm{C}(b) ; \mathrm{Ge}_{0.26} \mathrm{Se}_{0.74}$ as-deposited (c).

composition range can be achieved which is of interest for a study of photo-structural changes in this system.

The IR spectra measured in a $\mathrm{Ge}_{0.34} \mathrm{Se}_{0.66}$ and a $\mathrm{Ge}_{0.64} \mathrm{Se}_{0.36}$ layer (see Fig. 8) show a strong absorption band at $260 \mathrm{~cm}^{-1}$ which is due to the $v_{3}$ mode of the $\mathrm{GeSe}_{4}$ tetrahedra. The Ge-rich films were also unstable in air and showed in their IR spectra strong absorption bands of $\mathrm{Ge}-\mathrm{O}$ vibrations, increasing in intensity when keeping them in air for a long time.

In Fig. 9 the Raman spectrum of an as-deposited $\mathrm{Ge}_{0.34} \mathrm{Se}_{0.66}$ film is shown (curve $a$ ). We observed five significant bands: a strong band at $200 \mathrm{~cm}^{-1}\left(A_{1}\right.$ peak), a side band around $210 \div 220 \mathrm{~cm}^{-1}$ (called the companion line, $A_{1}^{c}$ ), a peak at $188 \mathrm{~cm}^{-1}$, a broad band at $280 \mathrm{~cm}^{-1}$ and a peak at $175 \mathrm{~cm}^{-1}$. The $A_{1}$ peak at $200 \mathrm{~cm}^{-1}$ can be assigned to the symmetric-stretch breathing mode of the $\mathrm{GeSe}_{4 / 2}$ corner sharing tetrahedra [6]. The companion line $A_{1}^{c}$ at $220 \mathrm{~cm}^{-1}$ has been assigned to vibrations of the Se atoms in four-membered rings composed by two edgeshared tetrahedra [7]. The bands at 280 and $175 \mathrm{~cm}^{-1}$ were assigned to the vibrational modes of a structural unit containing $\mathrm{Ge}-\mathrm{Ge}$ bonds such as $\mathrm{Se}_{3}-\mathrm{Ge}-\mathrm{Ge}-\mathrm{Se}_{3}[8]$. The peak at $188 \mathrm{~cm}^{-1}$ can be associated with the vibration of selenium atoms in a tetrahedral molecule in which a Se atom is replaces by a Ge atom [9]. All these features indicate that homopolar $\mathrm{Ge}-\mathrm{Ge}$ (and probably Se-Se) bonds are present in the sample with slight overstoichiometry of Ge.

The $\mathrm{Ge}_{0.34} \mathrm{Se}_{0.68}$ film was annealed at $300^{\circ} \mathrm{C}$ for $1 \mathrm{~h}$ in nitrogen atmosphere. The Raman spectrum recorded after heating (curve $b$ in Fig. 9) suggests that structural changes have occurred: the intensity of all the bands associated with $\mathrm{Ge}-\mathrm{Ge}$ bonds has decreased. The new spectrum resembles that of $\mathrm{Ge}_{0.26} \mathrm{Se}_{0.74}$ (curve $c$ ), which is less Ge rich.

\section{Conclusion}

We have been able to prepare layers of amorphous Se, and of the As and Ge chalcogenides ( $\mathrm{S}$ and $\mathrm{Se}$ ) by using plasmaenhanced chemical vapour deposition. The composition range of the binary systems which can be achieved by this technique is very broad.

\section{References}

[1] G. Lucovsky, A. Mooradian, W. Taylor, G.B. Wright, R.C. Keeze. Sol. St. Commun., 5, 113 (1967).

[2] G. Lucovsky. In: The Physics of Selenium and Tellurium, ed. by E. Gerlach and P. Grosse (Springer Verlag, Berlin, 1979) p. 210.

[3] P. Nagels, R. Callaerts, M. Van Roy, M. Vlček. J. Non-Cryst. Sol., 136\&137, 1001 (1991); Proc. Int. Conf. Cond. Matter. Phys. and Appl., ed. by W.E. Alnazer (Bahrain, 1992) p. 67.

[4] H. Fritzsche, V. Smid, H. Ugur, P.J. Graczi. J. Phys. C, 4, 699 (1981).

[5] E. Sleeckx, P. Nagels, R. Callaerts, M. Van Roy. J. Phys. IV, C3, 419 (1993); J. Non-Cryst. Sol., 164-166, 1195 (1993).

[6] S.E. Griffiths, G.P. Espinosa, J.P. Remeika, J.C. Phillips. Phys. Rev. B, 25, 1272 (1982).

[7] G. Lucovsky, C.K. Wong, W.B. Pollard. J. Non-Cryst. Sol., 59-60, 839 (1983).

[8] Nemanich, G.A. Connell, G.A. Hayes, R.A. Street. Phys. Rev. B, 18, 6900 (1978).

[9] H. Kawamura, M. Matsumura, S. Ushioda. J. Non-Cryst. Sol., 35-36, 1215 (1980).

Редактор Л.В. Шаронова 